\title{
Gatekeepers Rather than Helpless: An Exploratory Investigation of Seniors' Use of Information and Communication Technology in Critical Settings
}

\author{
Stan Karanasios \\ RMIT University \\ stan.karanasios@rmit. \\ edu.au
}

\author{
Vanessa Cooper \\ RMIT University \\ vanessa.cooper@rmit. \\ edu.au
}

\author{
Anouck Adrot \\ Paris-Dauphine University \\ anouck.adrot@dauphi \\ ne.psl.eu
}

\author{
Bernadette Mercieca \\ RMIT University \\ bernadette.mercieca@ \\ rmit.edu.au
}

\begin{abstract}
Reports and studies often show that seniors suffer disproportionately during disasters. Yet seniors' handling of information and communication technology is largely overlooked. Based on a qualitative study comprising interviews and focus groups, this research shows important properties of seniors' practices with information in critical settings. Seniors embody and tap into local knowledge, mingle offline and take online cues about emergency situations, and maintain trust towards institutions. We discuss the need to pursue and diversify investigation on this topic, as well as the role of seniors as gatekeepers rather than considering them helpless individuals. This research contributes to a better understanding of seniors' use of digital resources by highlighting their role in information sharing in disaster settings. We pave the way for future research to inform policy making and support seniors' survival in future disasters.
\end{abstract}

\section{Introduction}

Reports examining the impact of disasters, such as fires, hurricanes, floods, heatwaves and other natural phenomenon regularly indicate that seniors are disproportionately impacted. For instance, in the aftermath of the 2005 Hurricane Katrina in the USA [1]; 2011 earthquake and tsunami in Japan [2]; 2003 heatwave in France [3]; and 2013 Typhoon Haiyan in the Philippines [4], persons aged over 60 represented up to $90 \%$ of victims; even though in some cases they only accounted for one tenth of the population. This is a major concern given two major global challenges are a projected growth in the number of older persons from 901 million in 2015 to more than 1.4 billion in 2030 [5] and an increase in the frequency and intensity of extreme weather-related disasters [6].
The United Nations [7] define seniors (or older persons) as being aged 60 and over. Seniors are often exposed to multiple risks and lack of mobility that make information access and transmission crucial for their safety in critical settings. They are more likely to live with interrelated risk factors [8]. These include chronic conditions which can deteriorate quickly, being slow or reluctant to evacuate and seek assistance, transportation issues, past experience with false positives, limited resources and being poorly informed, isolation, abandonment by carers and, being difficult to empower [3, 4, 8-13]. The situation is compounded when considering the long-term health effects and mortality. In the year after Hurricane Katrina, in addition to the increase in mortality, the health of survivors aged 65 or over showed a considerable decline [14]. Likewise, during prolonged evacuations, displaced older persons with chronic medical conditions may not have access to their usual medications [11]. Seniors also show a strong intention to remain where they are before and during disasters. For instance, across different periods, cultures and types of disasters - e.g. the 1979 Three Mile Island accident, 2005 Hurricane Katrina and 2011 Japan Earthquake - older persons were found to be less likely to evacuate [15-17], which implies the need to maintain connection and share information with them. Thus, it can be argued that the role of information and communication is paramount to seniors in this context [18].

So far, research has provided limited insights on the opportunities and challenges that need to be overcome to make ICT a significant lever for seniors' survival and well-being before, during and after disasters. Given the projected growth in the number of older persons and increasing diffusion of ICT worldwide, there is a need for further examination of the ICT practices of seniors [19]. Extant research shows seniors are less likely to use ICT than the general population [20] due to a range of individual preferences, limitations and design factors [21-24]. However, in addition to the demographic forecasts 
mentioned herein, evidence clearly suggests that the quality of information sharing and communication has tangible implications for health and survival [3, 11]. Information is a vital form of aid and can save lives, livelihoods and resources [25, 26]. This renders urgent the need for a better understanding of seniors' relationship to ICT in critical settings.

Relying on focus groups and interviews, this paper investigates seniors' perception and use of ICT during disasters. The analysis outlines some features from this population that contradict the widespread cliché that views seniors as a helpless population. Participants fully acknowledge their need to maintain informational ties with other actors, as well as their appetite for precise and reliable information. Awareness of their own limitations, as well as their experience and knowledge of disaster settings, account for seniors' capability for agile reliance on sources of information. We address the research question: In the context of disasters, how do seniors perceive and use ICT information sources? In answering this question we consider the broader information ecology and discuss implications from our findings that cover seniors' skills that mitigate emergent dynamics that can jeopardize disaster response. The contribution of this work is twofold. First, it paves the way for further investigation of the role of seniors in information reliability in disaster settings. Second, it questions commonly held perceptions of seniors and approaches them as information gatekeepers, who while still need support to handle their own limitations, can alleviate disturbances and noise in emergency response.

\section{Literature review}

There is limited research that focuses specifically on seniors, ICT use and disasters. Our review is divided into two parts. First, we review studies that examine the specificities of disasters, their impact on seniors and their actions focusing on research in the fields of disasters, institutional reports and studies that have considered the role of ICT. Second, we draw on studies that examine the use of ICT by seniors, and the factors influencing their use, drawing predominantly from the field of information systems. The two streams inform the study by suggesting the role of ICT in disasters by seniors and the challenges to its use. It also shows that ICT can mitigate the gaps in information and services, and how seniors can use ICT to draw on their own information networks to inform decision making and action.

\subsection{Disasters and seniors}

Natural disasters, such as bushfires, earthquakes, tornadoes and floods, are high-velocity, unpredictable and time-critical incidents, which require departure from routine practice and place unfamiliar demands on individuals [27]. They provide rich settings for studying human response to non-routine events from the perspective of psychology (e.g. regarding emotion, cognition and related actions during response); mathematics and engineering (e.g. analyzing evacuation response through modelling) and societal studies (e.g. on the impact of disasters and organizational response).

\subsubsection{A partial understanding of seniors' behavior} in critical settings. Scholars' attention has been increasingly attracted towards how individuals use digital technologies to access and share information, as well as handle critical events. According to this literature, seniors represent a significant proportion of the most vulnerable population. However, with few exceptions [1], studies tend to ignore seniors' specificities and approach them as a small group in a broader sample and are lumped with other vulnerable groups [17]. For instance, recent work on the management of vulnerable and disabled persons in the aftermath of earthquakes comprise the seniors in the sample under investigation [28] without any other distinction than age. The lack of understanding and documentation of seniors' specificities results from early focus on extreme age as being a major source of vulnerability [29]. While the full integration of seniors into the scope of investigation in crisis management is overall positive, the lack of knowledge on this topic can result in misleading conclusions and policies.

The literature on seniors highlights the behavior of this part of the population is far more complex than what it seems at first sight. Radically divergent features embodied by people above 60 years old, from altruistic behavior and leadership skills [30] to aggressive behavior [31] have been reported. Thus, scholars and practitioners still need a comprehensive account of seniors' behavior in critical settings.

2.1.2. The role of agencies and the wider community. A partial understanding of seniors' behavior in critical settings comes with the common assumption made by governments and institutions that seniors are looked after by their community or family [11] and therefore information and mass distributions will reach them [10]. Seniors in close contact with friends and neighbors are more likely to survive, as their vulnerability is recognized earlier, while those people 'invisible' to society suffer most [3]. An alternative assumption is that the needs of 
seniors will be met by specialist agencies. Yet there are few agencies and NGOs dedicated to seniors specifically [10]. While many seniors have strong community networks or may have their information needs met by certain agencies, reports have argued that agencies and the wider community (which includes family, friends, public health authorities and elderly-care professionals), should intervene to ensure the safety of elderly people $[3,32]$.

The institutional focus on seniors is uneven and fractured. Examples exist where seniors have been given prominence as well as neglected. For instance, specific plans dedicated to seniors' care were established by the Ministry of Health in the aftermath of the 2003 heat wave in France. One of them involves the French Red Cross which mobilizes its volunteers to carry out specific activities, targeting the most vulnerable sectors-including seniors, by making home visits, and by encouraging isolated seniors to register with their district authorities [33]. By doing so, it strengthens solidarity and resilience and deals with the problem of isolated seniors most at risk. On the other hand, within the existing preparation guides there are very few references to the unique needs of older persons [34] and their needs are not integrated into the guidelines and technical response mechanisms available to the emergency and humanitarian community [35]. For instance, a report of the International Federation of the Red Cross found there were few references to older people in the Tsunami Evaluation Coalition's (TEC) 2006 synthesis report, other than to note: "TEC studies found that in general the needs of vulnerable groups (women, the elderly and children) tended to be overlooked" [10]. More recently, a study of social media posts by institutional actors found that only a fraction of posts provided tailored information for seniors and such posts typically focus on reminding the general public to check-in on seniors [36].

2.1.3. Resilience and the role of ICT. A neglected dimension of the literature is the value seniors can offer from their past experiences of surviving disasters. There is evidence to suggest that they play invaluable roles and can be central to the development of community coping and information strategies during and after disasters [37] and often draw on modern technology such as social media [9]. This is important, as it demonstrates that rather than viewing seniors as helpless, many can, and want to, contribute to the welfare of their community. For instance, in 2006 when the Iranian city of Bam was destroyed by an earthquake killing over 26,000 people, disaster response experts were helped by local elderly men of influence who organized community responses across the city [10]. Other examples include the young urban dwellers meeting with the elderly in the mountains to learn together about the risks and lessons from typhoons [38]. Such examples suggest the experience and willingness of seniors to participate in disaster response. The resilience of seniors can be magnified by ICT. In industrialized societies in particular, there is potential for the increasingly tech-savvy older generation to [39] contribute to disaster resilience via participation in research and knowledge translation that focuses on the applications of ICT to disaster management [8].

The literature on information behavior and technology use in disasters has privileged social media in recent years. Research following the Japan Tsunami showed that in parts less effected by damage to the power infrastructure Twitter use rose from an average of 3,000 inter-country messages per minute to 11,000 on the day of the earthquake [40]. Within the first hour after the earthquake, a Twitter hashtag was created by a user in Southern Japan as a focal point for requests for assistance and Twitter Japan created tags for specific information needs such as, for example, evacuation centers and information. Other platforms such as Mixi and Facebook and Google's Person Finder provided a way for survivors to locate friends and family and let people know that were safe [40]. A challenge with these studies is that they neglect the broader information ecology comprising other information tools and informal and formal networks [41]. Significantly, in Tohoku, the most effected region, the most frequently used communication tool on the day of the earthquake was radio [40] which offered real-time local information that affected decisionmaking [34]. Thus one of the recommendations was that it is necessary to evaluate and address the specific information needs of the elderly and other vulnerable groups at times of disasters who may sit on the periphery of the information society [40].

\subsection{Studies on seniors and ICT}

Despite awareness of ageing populations and the increasing diffusion of ICT worldwide, there has been limited research dedicated to examining the factors that influence seniors' intention to use, and their actual use, of ICT [19]. Of the research undertaken, a commonly drawn conclusion is that older people are less likely to use technology than all other age groups [20]. This is attributed to factors such as seniors' privacy concerns [21], computer anxiety [22], perceived complexity of technology and insufficient knowledge and skills [23, 24], lack of 
interest and perceived benefits [23, 39], cost deterrents and physical limitations [23].

Studies of seniors and ICT often raise concerns for the "digital divide" that highlights the gulf between those who have access and use ICT and those who do not. The implication being, that seniors who are less likely to use ICT when compared to younger populations, risk losing out on benefits such as increased social and self-understanding, improved interaction and completion of task-oriented goals [42]. While research highlighting the digital divide between younger and older persons is valuable, it risks treating older populations as a homogenous group at the expense of obtaining in-depth understanding of the diversity of seniors [43]. To identify the factors that influence seniors' adoption of ICT in a more nuanced way, studies underpinned by technology acceptance models such as TAM, DOI, UTAUT and UTAUT2 [44-46] have considered control variables such as age, gender, experience and education. For instance, a survey of 278 Portuguese seniors found that performance expectancy, effort expectancy, social influence, facilitating conditions, hedonic motivation and habit significantly influenced seniors' intention to adopt ICT, whereas price did not. Of four control variables (experience with Internet use, level of education, gender and age), only the level of education and Internet experience had a significant impact on the use of ICT by seniors [43].

Literature on seniors and social networking more specifically, concentrates on the ability of ICT to address social isolation $[47,48]$ and on understanding why seniors use or avoid social networking and social media [21, 49]. Thirteen domains were identified in literature on seniors and social networking and social applications [47]. Amongst these domains, the potential to stay in contact with family was a primary motivation for adoption, while privacy concerns was a key barrier. As ageing is associated with less social interaction and lower levels of belonging and wellbeing [50], understanding the potential of social networking to meet the information seeking and interactional needs of seniors is important. In a quantitative study of 280 senior users of Facebook it was shown that older users can derive feelings of social connectedness via online social networks, which is an important insight given seniors may be less likely to connect face-toface [48]. A qualitative study of 20 Facebook users and 26 non-users, showed that motivations to use the site were keeping in touch, sharing photos, social surveillance, responding to family member demands to join, convenient communication with others and curiosity [21]. Reasons for non-use included privacy concerns, need for media richness, preference for familiarity, triviality of communication, time commitment and limited skills [21].

\section{Research study}

\subsection{Research design}

We undertook a study examining seniors use of technology mediated information behavior during disasters in a state of Australia. The broader study focused on the intersection of organizational actors, digital technology and communication and vulnerable communities $[36,51]$. In this paper we focus our efforts of the practice of seniors. We followed an interpretive approach, which is well-suited to illuminating information systems use [52] and allowed us to examine in detail individual ICT use and information practices as well as explore the challenges seniors face in accessing relevant information and using ICT. The study demanded the need for an understanding of the context in which seniors enact information behavior, construct sensemaking and their subsequent responses. Thus, a qualitative method for data collection was selected.

\subsection{Data collection}

The sampling process occurred in two ways. First, we reached out to a range of community groups whose member bases constituted a base of older persons. Second, we promoted the research through the Council for the Aging and similar groups that were able to distribute our study aims. In total we collected data from 47 participants across interviews and two focus groups.

During the interviews and focus groups, participants were encouraged to reflect on their previous experience during a range of incidents rather than focus on a specific incident. Most commonly they referred to bush fires, floods and storms. This approach is particularly useful, and common, when it is not feasible to observe or wait for an activity or event, such as a disaster to unfold.

As interviewees reconstructed the events, they were asked a series of probing questions to help focus on the role of ICT and information. The interviews focused on sources of information, digital tools used and practices. The focus groups followed similar questioning but also allowed for interactions across participants on issues such as ways to improve information and challenges with the use of current technology. Interviews were conducted face-to-face in community centers or over the phone. With consent, most interviews were audio-recorded, or comprehensive notes were taken, allowing the 
discussion to be reconstructed immediately after the interview. All focus groups were conducted face-toface in community centers and recorded with permission. Interviews and focus groups were approximately 35 minutes duration.

\subsection{Analysis procedure}

The interviews and focus groups were transcribed verbatim and entered into NVivo qualitative software for analysis, as were notes and memos. In total, 341 pages of qualitative data were analyzed. Saturation point was reached when no new themes emerged from the data. Our coding sequence followed the logic of open coding, axial coding, and selective coding, and the constant comparative method [53]. To ensure a systematic and reliable coding process, two authors analyzed each transcript; after analysis of each transcript we compared and contrasted codes to negotiate a consolidated yet evolving code book. The codes that emerged comprised 'communication tools and information sources' (with sub-codes: broadcast media, social media, internet and online information, mobile phones, local signs, and official warnings and alarms); 'reliance on and contributions to community' (with sub-codes: social support and community involvement); and 'experience with previous disasters' (with sub-codes: type of disaster, past responses, failed communication). Through multiple rounds of axial coding we identified relationships among the open codes. As our analysis developed, we applied selective coding to address our research question, focusing more on conceptual abstraction (or the 'story-line') based on our insights into the research [53]. This allowed us to manage the volume of data and constantly organize codes into a coherent structure. In the analysis presented here we rely heavily on interview quotes and examples as interpretative evidence that illustrate "codable moments"; building an analytical and explanatory narrative account.

\section{Findings}

The analysis revealed a diverse picture of seniors' varied perceptions and use of ICT. This included their preferred choice of communication tools and information sources, their reliance on and contributions to communities and the level of experience they had with disasters. Findings showed differences between those who lived in rural locations, who were the majority in this study, and those living in either outer metropolitan or metropolitan settings. This included their community involvement and the extent to which they relied on their community for support. The findings also revealed the ways in which communication has failed in the past in regard to disaster information and the implications this may have for policy making. The findings are structured by focusing on different types of ICT and non-ICT information sources and types of information accessed and shared. By considering the underlying motivations of seniors that drive their choice of both ICT and non-ICT information sources, a more complete picture of their information ecology in disasters can be developed [54].

\subsection{ICT information sources}

4.1.1. Broadcast media. It was clear in this study the preferred source of information for older participants in regard to hazards and disasters was that given by trusted reporters on radio and television. As P11 reflected, "I've watched that (TV) every day, now, for 20 years, and... I said to people, it's pretty well absolutely spot on". Participants valued the immediacy of these media, "one click and it's on" (P1) as well as its familiarity. They also acknowledged the ready availability of these media as few households would lack a television and cars all have radios, whereas not all participants would have access to computer/internet and mobile phones. As P18 reflected, "Some of the older people don't use apps at all, but they have the radio".

One particular broadcasting source was valued above all others in terms of accessing information in an emergency: a 24 hour news source and radio channels such as 774 and Radio National run by the national broadcaster. Often it was the only free-to-air broadcaster in rural regions: "We always rely on the ABC (Australian Broadcasting Cooperation)" (P4). Participants valued the fact that the $\mathrm{ABC}$ was continually releasing updates: "And there's a thread. It'll come every 15 minutes or every so often, so they update, and they follow through with it" (P4). They also appreciated the precision of the visual information, "Exactly what was happening and where it was happening" (P17). Those in regional areas valued the fact that local $\mathrm{ABC}$ programs highlighted local emergencies: "It wouldn't affect Melbourne TV, but it would come through Ballarat, for instance" (Focus group participant). Other participants relied on the ABC and other TV news sources to hear the weather for the coming day. This was an important source of information as it determined what activities they might do the next day.

A significant advantage of radio as opposed to television was that it was accessible in vehicles. This is particularly important for rural participants who might have to travel considerable distances each day 
to either work or access commercial services in nearby towns, "We have the radio going when we're travelling" (P14). Sometimes the areas they passed through were inaccessible to mobile phones meaning the radio was their only companion. Radio was valued for being a comprehensive source of information covering a variety of conditions: "They give weather alerts and pollen counts and storms and bushfire information all the time ABC Radio" (P18). The currency and immediacy of the information provided was particularly valued by P14 who liked the fact that they were "talking in real time".

4.1.2. Mobile phone. Most participants had access to a mobile phone and many used it to access information about local fires and emergencies. One highly trusted information source was the Country Fire Authority (CFA) and its App, not least because many local residents were part of their local CFA. As P18 reflected: "We're all in touch with the CFA. Everyone I know has got the same App on their phone." The CFA App was valued because of the updates it provided wherever one happened to be. As P17 noted, this information was important if they or their partner were out on the road: "There was a concern if [a fire] might come up the highway and my husband got a message on the phone to say there were fires in the district."

Some participants had been in the position of having their child or their friend putting the CFA App on their phone for them, but they did not really know how to use it. However, the fact that notifications came through automatically was advantageous as they could access the information without having to use any other technical skills. Others, particularly in the older age groups might have been given a mobile phone by their family but did not know how to manage it: "You know what, they have to find their phone! Half the time their phones are flat" (Focus group participant). Mobile usage appeared to be often supported by participants' children, who tended to be the ones who helped them download the relevant Apps and encouraged them to keep their mobile charged. P18 noted: "They said okay mom, yeah, whatever, you know, connect the mobile and charge it up and yeah-yeah, I'll do that."

The issue of limited mobile reception in country areas also meant that some participants lost reception at critical moments. P18 noted the frustration that this caused: "And, um, you're following it on the radio and on your phone, and then all of a sudden all the reception goes and you don't know, the winds changing, you don't know how fast and you don't know which road to take, you know, east or west sort of thing." This has implications for state governments and telecommunication providers, given that country roads are some of the most dangerous areas for seniors to travel and these areas are more likely to have poor mobile phone coverage.

4.1.3. Online information. Websites were also valued sources of information for participants. This included the CFA and weather websites. P12 used a CFA site to find local updates and determine her course of action: "To see where little fires might be popping up and all that sort of thing because we need to know. If I'm here on my own if I can I would leave." Participants such as P4 and P5 both valued the more detailed information that websites provided. Whilst the TV might provide a good overview of a developing situation, the website provided the finer details. P8 found the Vic Emergency website his preferred medium for accessing information because of the way he could tailor it to suit his needs: "Yes, the Vic Emergency website's very informative and I often just filter out everything but the fires, that's what I need to be following." Others such as P17 just liked to have the CFA website on in the background: "We didn't stay on all day. We just go on intermittently to check out what's going on." Weather sites were also important for participants such as P9, providing them seven day forecasts around which to plan their activities.

4.1.4 Social media. Participants varied in the level of value placed on the veracity of information on social media. The majority viewed social media (predominantly Facebook) primarily or exclusively as a tool for connecting with their families. Knowledge of how emergency services organizations use social media was relatively low and women tended to be greater users of social media for understanding potential threats. A smaller group (predominately the younger participants) used Facebook to connect with their local community. For example, P17 felt that Facebook was a preferred media because of its local focus: "Yeah, Facebook was good because we got local content of what was happening around the area". P14 also used Facebook to connect with a number of local groups including her local council with whom she felt confident would put up key information during any local emergency. The visual aspect of Facebook was emphasized by P12 who found it helped her to assess details about the extent of a local fire: "There's been a lot of posts related to that on the local sort of various local Facebooks and things that seem to come through. So, I spent an hour or more on it the other night."

Participants who had a negative response to social media ranged from those who had never used it or 
felt no need for using it but felt no animosity towards it to those who expressed outright scorn for it. A negative response was evident in less than half of the individual interviews, although a number of negative comments about social media appeared in each of two focus groups. Typical negative responses included those of Focus Group 2 participant, "I would if I had all the stuff to use it with but I haven't and I've no intention of getting it" or P1 from the older age group, who felt getting it was just too much bother: "No, no really, by the time I've got myself on the right thing the catastrophe will be over. You know, I can operate a computer, but I'm not a whizz on it." Some non-users of social media explained that they rely on users of social media for information and passing on up-to-date information. These comments reveal that these participants, whilst not totally opposed to the use of social media, feel no immediate need to familiarize themselves with it. It would appear, that despite the findings of researchers [55], utilising social media to access disaster information has failed to make a large impact on elderly people, particularly in rural commumities.

\subsection{Non-ICT information sources}

4.2.1 Local authorities. It became evident in this study that local authorities can have a positive influence on the degree to which older people are informed about disasters. This included both the influence of the local council with its signs and alerts and the support of often very close-knit communities.

A number of participants referred to the alarms that went off when a bushfire or other weather event such as a cyclone was close by. As one focus group participant reflected, "If it's a cyclone and that they've got that siren that makes you look!" Some felt the alarm went off too often for minor incidents, but as P9 rationalized "it's better to warn people too much than not enough". The value of these alarms also appeared to be that they alerted a lot of people who, as a focus group participant reflected, would try to find out what was amiss by seeking additional information from both ICT and non-ICT sources.

Apart from sirens, local councils also often provided signs at the entrance to their towns indicating the level of fire danger. P1 referred to, "an indicator in the town that, that has a, sort of, a signal on it, like an arrow that points if we're moving into high danger periods". Signs such as these would appear to be particularly helpful to visitors and passing travelers who might not be aware of dangers in the area. Other councils provided regular newsletters and flyers particularly during the summer months. Newsletters tended to emphasize preparatory measures that residents should take such as cutting grass and clearing gutters. Flyers were often placed in local libraries, around the shops, at the Senior Citizens and Bowls clubs. P14 also valued the fact that the Senior Citizens' room was open to locals seeking relief on very hot days, as well as picking up those who did not have transport.

4.2.2. Local knowledge and networks. One of the key themes to emerge from the data was the way in which older people, in rural areas in particular, both contributed to and relied upon their local community for information and support. These networks and relationships played a key role in helping people make sense of local emergencies. This occurred via formal and informal approaches.

A number of participants spoke about the importance of phone trees. This is a simple list of phone numbers linked to around 16 households. As P9 explains each person in the network has two or three numbers of people they can ring, "because what we need is extra eyes and ears and bits and pieces, you know, have you seen anything, what's happening, whatever, whatever, whatever". The first person who hears about something would ring their neighbor, and then they'd ring the next one and so on. For example, P12 spoke about getting a call from their phone tree about a log blocking the road. On another occasion, a neighbor rang them quite late in the evening to say that there was a glow of fires over their way. P12 could not see the same glow from their place but knowing that his neighbor had was important preparatory information. A more urgent message came to P2 from the phone tree about how his neighbor planned to leave their house because of an approaching fire. The caller was asking if they were planning to do the same. Some participants commented that the phone tree has largely been superseded by a What's App chain but with a similar concept lying underneath it. This is a remarkably simple concept but the resulting benefits from accurate and localized information flowing within a community network should not be under-estimated.

A number of participants spoke about the local knowledge about disasters that they had built up over a number of years that served them well in times of difficulty. For some, this involved being very watchful. P16 talked about "keeping an eye on the wind direction", others in the focus groups talked about looking for smoke in the sky, whilst P18 spoke of a deep inner knowledge built up over many years: "We all know what to do. We've all got our fire plans and we all know to go across to the school where the emergency, um, meeting points are." P2 spoke about "knowing what your limitations are and making sure 
you know what you're doing if you stay." They summed up that this personal vigilance relied on a precise knowledge of the area "And we, I mean, we know this area better than Vic Emergency".

Data from rural participants showed that participants informed and supported each other. Many had lived in their local areas for many years and knew their neighbors well: "They've known each other since kindergarten!" (P13). In particular, they were very aware of more elderly members of their community who might not be accessing the type of information that they were accessing. P1 spoke of an elderly neighbor close by who he would call in on if there was an emergency in the area: "I would be aware of my neighbor and he would also be aware of me although he's a few older than me, he's 82 or three or whatever. So, it will be more likely I'd be running in there faster than he could be getting in here". Similarly, P15 spoke about friends who were single or widowed who they would be in touch with to ask if they needed any help. P18 summed it up, "I think anybody who is in a vulnerable situation has a network, and of course everyone would jump in and help them". The strength of these community networks cannot be under-estimated and were seen to be strengthened via connections to local agencies.

\section{Discussion and conclusion}

Seniors suffer disproportionately during disasters while their behavior remains under-analyzed in the crisis management literature. Extant research points to their crucial need for information access and sharing based on their exposure to interrelated risks and lack of mobility. However, their usage of information technologies with respect to stochastic, high-velocity events has remained underexplored. This study addresses this gap, emphasizing that seniors are not simply passive victims and highlighting their appetite for precise and reliable information. In addition, when faced with incomplete or absent official information they are able to draw on ICT to share information, connect and fill information needs. It also suggests that they are a valuable source of knowledge and experience in the context of disasters.

It is clear that agencies, NGOs, community organizations and the wider community need to take into consideration the information needs as well as ICT preferences and practices of seniors in the context of disasters [3]. While, there are few studies to draw direct comparisons in the information systems literature and beyond, our study of seniors' use of ICT in critical settings has important theoretical and practical implications.
Theoretically, our study has provided an understanding of the information ecology of seniors and highlighted the importance of both offline and digital information sources. The physical-digital mashups reported in this study has shown how different ICT and non-ICT information sources can complement each another as well as compete [54]. Online information, for example, is seen to supplement information provided by broadcast media rather than displace it; whereas phone trees are largely being replaced with What's App chains. For practice, our study highlights to policy makers that adopting strategies which emphasize newer technologies over existing technologies (e.g. strategies which displace traditional broadcast media in favor of social media) may not be appropriate in the crisis context, particularly when considering the information needs and preferences of seniors. Future research might focus further on the underlying motivations and dispositional needs of seniors which drive their choice of communication mediums and usefully adopt competing and complementary conceptual lenses to examine crisis communication to enable important new insights to emerge.

Our findings also suggest that the quality, type and source of information is linked to the subsequent actions of seniors, which can have very tangible implications [18]. A thorough investigation of the role of the nature of ICT affordances on seniors' resilience is warranted. In our study, factors such as perceived ease-of-use (e.g. not all seniors are confident to use mobile phones and apps) and perceived usefulness (e.g. participants held diverse views on Facebook) influence seniors' choice of information sources [43-46, 49]; in addition, some sources may not be available during a disaster (e.g. mobile phone reception in remote areas). Researchers and practitioners should also be mindful that many seniors do not regularly use digital media, and research is needed to examine the broader range of their information practices as well as understand how information flows from others' use of ICT to seniors [36]. This is critical, as the disaster literature shows that information is a vital form of aid and can save lives, livelihoods and resources [25, 26]. For seniors that may be socially isolated it may be the only form of disaster preparedness that they can afford [11].

Future research could build on the findings of this study by drawing on a more expansive sample. At the same time, as with other age groups, the diversity of older people must be recognized and captured in agedisaggregated data. In this paper we drew on the UN definition of senior people. However, future research could focus on different categories of older persons such as 'young old' (60-70), 'old-old' (70-80), and 
'oldest-old' (over 80) [56], as well as gender differences. By focusing on seniors as a social category in a more nuanced way, one can identify their commonalities and differences with other at-risk groups, such as disabled, or geographically or socially isolated. Going further, statistical analysis techniques, such as factorial and cluster analysis could help grasp various types of seniority with respect to information in critical settings and induce recommendations regarding their requirements. Future research should examine further the important role that seniors play as gatekeepers of information and knowledge and explore ways to tap into and magnify their potential contributions in this space.

Acknowledgements: This research was funded by the National Disaster Resilience Grant Scheme, Emergency Management Victoria.

\section{References}

[1] Gibson, M.J. and M. Hayunga, We Can Do Better: Lessons Learned for Protecting Older Persons in Disasters. 2006, AARP Public Policy Institute: Washington, D.C.

[2] Nakahara, S. and M. Ichikawa, Mortality in the 2011 Tsunami in Japan. Journal of Epidemiology, 2013. 23(1): p. 70-73.

[3] IFRC, World Disasters Report: From Risk to Reslilience - Helping Communities Cope with Crisis. 2004, International Federation of Red Cross and Red Crescent Societies: Geneva.

[4] Campbell, J.W. and J. Feather, Why Older Adults Face More Danger in Natural Disasters, in HuffPost. 2014.

[5] United Nations., World Population Ageing. 2015, Department of Economic and Social Affairs Population Division: New York.

[6] UNISDR, The Human Cost of Weather-Related Disasters 1995-2015. 2015, The Centre for Research on the Epidemiology of Disasters; The United Nations Office for Disaster Risk Reduction: Geneva.

[7] United Nations., Political Declaration and Madrid International Plan of Action on Ageing. 2002, Second World Assembly on Ageing, Madrdi, Spain. 8-12 April 2002: New York.

[8] Gibson, M., et al., Expanding the Technology Safety Envelope for Older Adults to Include Disaster Resilience, in Technologies for Active Aging: International Perspectives on Aging, A. Sixsmith and G. Gutman, Editors. 2013, Springer Science+Business Media: New York.

[9] Bodstein, A., V. Lima, and A.M.A.d. Barros, The vulnerability of the elderly in disasters: the need for an effective resilience policy. Ambiente \& Sociedade, 2014. 17: p. 157-174.

[10] IFRC, World Disasters Report 2007 - Focus on discrimination. 2007, International Federation of Red Cross and Red Crescent Societies: Geneva.
[11] Ripley, A., The Unthinkable: Who Survives When Disaster Strikes - And Why. 2008, New York: Crown Publishers.

[12] Twigg, J., Disaster risk reduction: Mitigation and preparedness in development and emergency programming. 2004, Humanitarian Practice Network (HPN); Overseas Development Institute: London.

[13] United Nations., Current Status of The Social Situation, Wellbeing, Participation In Development and Rights Of Older Persons Worldwide. 2011, Department of Economic and Social Affairs, Population Division (DESA): Geneva.

[14] Burton, L.C., et al., Health of Medicare Advantage plan enrollees at 1 year after Hurricane Katrina. The American Journal of Managed Care, 2009. 15(1): p. 13-22.

[15] Cutter, S. and K. Barnes, Evacuation behavior and Three Mile Island. Disasters, 1982. 6(2): p. 116-124.

[16] Groen, J.A. and A.E. Polivka, Going home after Hurricane Katrina: determinants of return migration and changes in affected areas. Demography, 2010. 47(4): p. 821-844.

[17] Lee, Y.-J., H. Sugiura, and I. Gečienè, Stay or Relocate: The Roles of Networks After the Great East Japan Earthquake, in Social Network Analysis of Disaster Response, Recovery, and Adaptation, E.C. Jones and A.J. Faas, Editors. 2016, Elsevier Science. p. 223-238.

[18] IFRC, World Disasters Report - 2005 Data or Dialogue? The Role of Information in Disasters. 2005, International Federation of Red Cross and Red Crescent Societies: Geneva.

[19] Choudrie, J., S. Pheeraphuttranghkoon, and S. Davari, The Digital Divide and Older Adult Population Adoption, Use and Diffusion of Mobile Phones: a Quantitative Study. Information Systems Frontiers, 2018: p. 1-23.

[20] Barnard, Y., et al., Learning to use new technologies by older adults: Perceived difficulties, experimentation behaviour and usability. Computers in Human Behavior, 2013. 29(4): p. 1715-1724.

[21] Jung, E.H., et al., Social networking in the aging context: Why older adults use or avoid Facebook. Telematics and Informatics, 2017. 34(7): p. 10711080.

[22] Ellis, R.D. and J.C. Allaire, Modeling computer interest in older adults: The role of age, education, computer knowledge, and computer anxiety. Human Factors, 1999. 41(3): p. 345-355.

[23] Carpenter, B.D. and S. Buday, Computer use among older adults in a naturally occurring retirement community. Computers in Human Behavior, 2007. 23(6): p. 3012-3024.

[24] Peacock, S.E. and H. Künemund, Senior citizens and Internet technology. European journal of ageing, 2007. 4(4): p. 191-200.

[25] Chiu, D.K.W., et al., Alert based disaster notification and resource allocation. Information Systems Frontiers, 2010. 12(1): p. 29-47. 
[26] Crowe, A., Disasters 2.0: The Application of Social Media Systems for Modern Emergency Management. 2012, Florida, United States: CRC Press.

[27] Schmidt, S. and E. Galea, Recommendations for different types of end-users, in Human behaviour in emergencies and disasters: A cross-cultural investigaation, S. Schmidt and E. Galea, Editors. 2013, Pabst Science Publishers: Berlin. p. 11-20.

[28] Phibbs, S., et al., Emergency preparedness and perceptions of vulnerability among disabled people following the Christchurch earthquakes: Applying lessons learnt to the Hyogo Framework for Action. Australasian Journal of Disaster and Trauma Studies, 2015. 19: p. 37.

[29] Buckle, P., Re-defining community and vulnerability in the context of emergency management. Australian Journal of Emergency Management, 1999. Summer 1998/1999.

[30] Mattis, M.C., Advancing women in business organizations: Key leadership roles and behaviors of senior leaders and middle managers. Journal of Management Development, 2001. 20(4): p. 371-388.

[31] Cohen-Mansfield, J. and P. Werner, Predictors of aggressive behaviors: a longitudinal study in senior day care centers. The Journals of Gerontology Series B: Psychological Sciences and Social Sciences, 1998. 53(5): p. P300-P310.

[32] IFRC, World Disasters Report 2001- Focus on recovery. 2001, International Federation of Red Cross and Red Crescent Societies: Geneva.

[33] IFRC, World Disasters Report 2009 - Focus on early warning, early action. 2009, International Federation of Red Cross and Red Crescent Societies: Geneva.

[34] IFRC, World Disasters Report - Focus on Technology and the Future of Humanitarian Action. 2013, International Federation of Red Cross and Red Crescent Societies: Geneva.

[35] IASC, Guidance note on using the cluster approach to strengthen humanitarian response. 2006, InterAgency Standing Committee.

[36] Poblet-Balcell, M., S. Karanasios, and V. Cooper. Look after Your Neighbours: Social Media and Vulnerable Groups during Extreme Weather Events. in Information Systems for Crisis Response and Management (ISCRAM) Asia-Pacific. 2018. Wellington.

[37] Haynes, K., et al., Australian bushfire fatalities 1900-2008: exploring trends in relation to the 'Prepare, stay and defend or leave early' policy. Environmental Science \& Policy, 2010. 13(3): p. 185-194.

[38] IFRC, World Disasters Report 2010 - Urban Risk. 2010: Geneva.

[39] Melenhorst, A.-S., W.A. Rogers, and D.G. Bouwhuis, Older adults' motivated choice for technological innovation: Evidence for benefit-driven selectivity. Psychology and aging, 2006. 21(1): p. 190.

[40] Appleby, L., Connecting the last mile: The role of communications in the Great East Japan Earthquake, in Internews. 2013.
[41] Davenport, T.H. and L. Prusak, Information Ecology. 1997, Oxford: Oxford University Press.

[42] Czaja, S.J. and C.C. Lee, The impact of aging on access to technology. Universal Access in the Information Society, 2007. 5(4): p. 341.

[43] Macedo, I.M., Predicting the acceptance and use of information and communication technology by older adults: An empirical examination of the revised UTAUT2. Computers in Human Behavior, 2017. 75: p. 935-948.

[44] Davis, F.D., Perceived usefulness, perceived ease of use, and user acceptance of information technology. MIS Quarterly, 1989. 13(3): p. 319-340.

[45] Rogers, E.M., Diffusion of Innovations, Fifth Edition. 2003, New York: Free Press.

[46] Venkatesh, V., et al., User acceptance of Information Technology: Toward a Unified View. MIS Quarterly, 2003. 27(3): p. 425-478.

[47] Coelho, J. and C. Duarte, A literature survey on older adults' use of social network services and social applications. Computers in Human Behavior, 2016. 58: p. 187-205.

[48] Sinclair, T.J. and R. Grieve, Facebook as a source of social connectedness in older adults. Computers in Human Behavior, 2017. 66: p. 363-369.

[49] Vošner, H.B., et al., Attitudes of active older Internet users towards online social networking. Computers in Human Behavior, 2016. 55: p. 230-241.

[50] Mellor, D., et al., Need for belonging, relationship satisfaction, loneliness, and life satisfaction. Personality and individual differences, 2008. 45(3): p. 213-218.

[51] Karanasios, S., et al. Inter-organizational collaboration, information flows, and the use of social media during disasters: a focus on vulnerable communities. in Hawaii Conference on Systems Sciences. 2019. Maui.

[52] Walsham, G., The emergence of interpretivism in IS research. Information Systems Research, 1995. 6: p. 376-394.

[53] Charmaz, K. and R. Mitchell, Grounded theory in ethnography, in Handbook of Ethnography, P.A. Atkinson, et al., Editors. 2001, Sage Publications: Thousand Oaks, CA. p. 60-174.

[54] Dutta-Bergman, M.J., Interpersonal communication after 9/11 via telephone and internet: A theory of channel complementarity. New Media \& Society, 2004. 6(5): p. 659-673.

[55] Verroen, S., J.M. Gutteling, and P.W. De Vries, Enhancing self-protective behavior: efficacy beliefs and peer feedback in risk communication. Risk Analysis, 2013. 33(7): p. 1252- 1264.

[56] Forman, D.E., et al., PTCA in the elderly: the "young-old" versus the "old-old". Journal of the American Geriatrics Society, 1992. 40(1): p. 19-22. 